\title{
Hubungan Kekuatan Otot Tungkai Dan Kecepatan Lari Sprint 50 Meter Dengan Kemampuan Dalam Lompat Jauh Pada Siswa Putra Kelas XI SMA Islam Bina Insani Langko Tahun Pelajaran 2017/2018
}

\author{
Elya Wibawa Syarifoeddin \& Maulidin \\ Dosen Pendidikan Olahraga IKIP Mataram
}

. If not given proper attention then the result of sprint and long jump will not achieve maximum results. This study aims to menhui correlation between the Limb Muscle Relationships and Sprint Running 50 Meters with Lopmat Ability far on the students of class XI SMA Islam Bina Insani Langko Lesson Year 2017/2018 "From the data analysis by using the statistical correlation Product Moment and correlation double obtained count value rxy1-count $>$ r-table, rxy2-arithmetic> r-table, rx1x2 -count <r-table, and Ryx1x2-arithmetic> r-table value. Thus rxy1, rxy2, and Ryx1x2 obtained significant results with a significant level of $5 \%$ while the value of $\mathrm{rx} 1 \mathrm{x} 2$ did not achieve significant results at a significant level of $5 \%$ so it can be concluded that the null hypothesis (Ho) rejected and alternative hioptesis (Ha) accepted as well vice versa hypothesis nil (Ho) is accepted and alternative hypothesis (Ha) is rejected. Thus it can be concluded that: "There is a Relationship of Limb Muscles And Running Sprint 50 Meters with Lopmat Ability Far on Student of Class XI SMA Islam Bina Insani Langko Lesson Year 2017/2018 ", "There is Relationship of Limb Muscles And Running Sprint 50 Meter with Ability Lopmat is far away at the Student of Class XI SMA Islam Bina Insani Langko Lesson Year 2017/2018 "," No relation Sprint Run 50 Meter and Muscle Limb Strength in long jump ", and" There is Limb Muscle Relationship And Sprint Run 50 Meter with.

\section{PENDAHULUAN}

Olahraga atletik merupakan dasar bagi cabang olahraga yang lainnya. Maka tidak berlebihan bila di tinjau dari sejarahnya bahwa atletik itu " ibu dari semua olahraga "(Mother Of Sport).Olahraga atletik merupakan jenis olahraga yang memiliki banyak macam cabang olahraga yang sering dipertandingkan diantaranya yaitu: lari jarak jayh, lari jarak pendek, lompat jauh, lompat jauh, lempar lembing, dll. Dari berbagai macam cabang olahraga atletik tersebut yang sering dipertandingkan juga memiliki keterkaitan diantaranya yaitu pada cabang lari sprintdengan cabang lompat jauh .

Kecepatan lari sangat dibutuhkan pada saat melakukan pertandingan pada cabang lompat terutama pada lompat jauh . Hasil lompat jauh akan maksimal jika kecepatan lari sprint bagus, begitu juga sebaliknya kalu lari sprint tidak terlalu bagus maka pencapaian pada saat lompat jauh tidak akan maksimal. Demi mencapai hasil lompat jauh yang maksimal maka sangat dibutuhkan kecepatan lari sprint yang cepat. Untuk mencapai kecepatan lari sprintmaka sangat dibutuhkan perhatian yang baik dan diiringi dengan latihan yang teratur.etapi kekuatan otot tungkai juga sangat berperan penting pada saat melakukan lari sprint dan lompat jauh . Jika otot tungkai tidak memiliki daya tahan yang efisien pada saat melakukan lari dan lompat jauh, maka hasil dari pada lari sprint dan lompat jauh tidak akan maksimal. Oleh sebab itu kekuatan otot tungkai harus benar-benar diberikan perhatian yang tepat demi mencapai hasil yang maksimal pada saat melakukan lari sprint dan lompat jauh . Jika tidak diberikan perhatian yang tepat maka hasil dari lari sprint dan lompat jauh tidak akan mencapai hasil yang maksimal.

Dari berbagai permasalahan latar belakang diatas tersebut, maka peneliti dapat menyimpulkan bahwa permasalahan yang harus diselesaikan adalah lari sprint, kekuatan otot tungkai, dan lompat jauh. Dari ke tiga permasalahan tersebut maka peneliti ingin menelit "apakah ada Hubungan Otot TungkaiDan Lari Sprint 50 Meter dengan Kemampuan Lompat jauh pada Siswa Putra kelas XI SMA Islam Bina Insani LangkoTahun Pelajaran 2017/2018?”.

Berdasarkan latar belakang di atas, maka peneliti mengambil sebuah rumusan masalah dalam penelitian yakni: 
1. Apakah ada Hubungan Otot Tungkai dengan Kemampuan Lompat jauh pada Siswa Putra kelas XI SMA Islam Bina Insani LangkoTahun Pelajaran 2017/2018?.

2. Apakah ada Hubungan Lari Sprint 50 Meter dengan Kemampuan Lompat jauh pada Siswa Putra kelas XI SMA Islam Bina Insani LangkoTahun Pelajaran 2017/2018?

3. Apakah ada Hubungan Otot TungkaiDan Lari Sprint 50 Meter dengan Kemampuan Lompat jauh pada Siswa Putra kelas XI SMA Islam Bina Insani Langko Tahun Pelajaran 2017/2018?

\section{METODE PENELITIAN}

Di dalam penelitian ini, peneliti menggunakan metode penelitian "Non eksperimen ". Penelitian non - eksperimen merupakan penelitian yang observasinya dilakukan terhadap sejumlah cirri (variable) subjek penelitian menurut keadaan apa adanya, tanpa ada manipulasi (intervensi) peneliti. Misalnya, penelitian mengenai kemunduran prestasi belajar siswa, kemunduran rasa tanggung jawab. Adapun bentuk rancangan yang dimaksud adalah seperti yang tertera pada gambar dibawah ini:

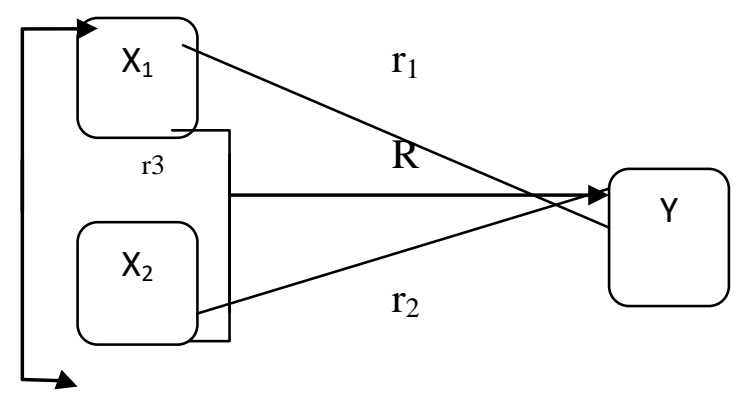

Gambar 3.1 Rancangan penelitian (Sugiyono, 2005: 7).

Berdasarkan rancangan tersebut diatas maka:

$\mathrm{X}_{1}$ : lari sprint 50 meter

$$
\mathrm{X}_{2} \text { :Otot tungkai }
$$$$
\text { Y: Lompat jauh }
$$

\section{HASIL DAN PEMBAHASAN}

Setelah melakukan penelitian, maka data yang didapatkan tersebut akan diolah terlebih dahulu pada tabel kerja setelah mendapatkan hasil dari tabel kerja, maka hasil yang didapat pada tabel kerja tersebut akan diolah lagi kedalam bentuk rumus dan rumus yang digunakan dalam penelitian ini adalah rumus product momen.
Ada empat tabel kerja yang akan digunakan untuk menentukan data yang akan dimasukkan kedalam rumus diantaranya yaitu:

1) Tabel kerja Lari Sprint 50 Meter $\left(\mathrm{X}_{1}\right)$ dengan kemampuan Lompat Jauh (Y)

2) Tabel kerja kekuatan Otot Tungkai $\left(\mathrm{X}_{2}\right)$ dengan kemampuan Lompat Jauh (Y)

3) Tabel kerja Lari Sprint 50 Meter $\left(\mathrm{X}_{1}\right)$ dengan kekuatan Otot Tungkai $\left(\mathrm{X}_{2}\right)$

4) Tabel kerja Lari Sprint 50 Meter $\left(\mathrm{X}_{1}\right)$ dan Kekuatan Otot Tungkai $\left(\mathrm{X}_{2}\right)$ dengan kemampuan Lompat Jauh (Y)

a. Memasukkan data kedalam rumus Data yang sudah ada pada tabel kerja, akan dimasukkan kedalam rumus " $\mathrm{r}_{\mathrm{xy}}$ " (Product Moment). Adapun nilai yang akan dimasukkan ke dalam rumus dari hasil tabel hitung product moment sebagai berikut:

1) Menghitung nila $\mathrm{i}_{x 1 y}$ hubungan lari sprint 50 meter dengan kemampuanlompat jauh

2)Menghitung nilai $r_{x 2 y}$ hubungan kekuatan otot tungkai dengan kemampuan lompat jauh .

3) Menghitung nilai $r_{x 1_{x 2}}$ hubungan lari sprint 50 meter dengan kekuatan otot tungkai.

4) Menghitung nilai $R_{Y X_{1} X_{2}}$ hubungan lari sprint 50 meter $\left(r_{x=1 y}\right)$ dan kekuatan otot tungkai $\left(r_{x 2 y}\right)$ dengan kemampuan lompat jauh .

1. Ringkasan statistik: $X_{1}$ dengan $Y$

\begin{tabular}{|c|c|c|}
\hline No & $\begin{array}{c}\text { Simbol } \\
\text { statistic }\end{array}$ & Nilai statistic \\
\hline 1 & $\mathrm{~N}$ & 30 \\
\hline 2 & $\sum \mathrm{X}_{1}$ & 160,83 \\
\hline 3 & $\sum \mathrm{Y}$ & 114,13 \\
\hline 4 & $\sum \mathrm{X}_{1}{ }^{2}$ & 881,8643 \\
\hline 5 & $\sum \mathrm{Y}^{2}$ & 438,4019 \\
\hline 6 & $\sum \mathrm{X}_{1} \mathrm{Y}$ & 616,1792 \\
\hline
\end{tabular}

a. Memasukkan data kedalam rumus

$r_{x_{1} x_{2}}=\frac{n \cdot\left(\sum x_{1} y\right)-\left(\sum x_{1 y}\right) \cdot\left(\sum y\right)}{\sqrt{\left.n \cdot \Sigma x l^{2}-\left(\sum x_{1}\right)^{2}\right\} \cdot\left\{n \cdot \Sigma y^{2}-(\Sigma y)^{2}\right\}}}$ 


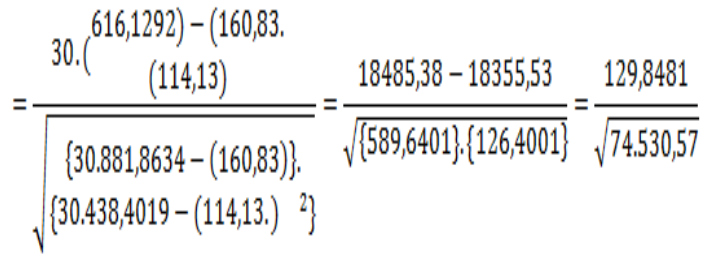

$$
=\frac{129,8481}{273,0029}=0,475
$$

b. Menguji nilai

Jadi ada tanda korelasi positif dengan nilai $\square_{\square l \square}$ sebesar 0,475 antara hubungan lari sprint 50 meter dengan kemampuan lompat jauh . Untuk menguji hasil $\mathbb{\square}_{\square l \square}$ signifikan atau tidak signifikannya, maka perlu dibandingkan dengan r-table. Pada r-tabel apabila taraf signifikan $5 \%$ dan $\mathrm{N}=30$, maka nilai harga $r$-tabel $=0,361$. Ternyata $r$-hitung lebih besar dari pada r-tabel, sehingga $\mathrm{Ha}$ diterima dan Ho ditolak. Jadi kesimpulannya adalah" ada hubungan lari sprint 50 meter dengan kemampunlompat jauh .

\section{Ringkasan statistik: $X_{2}$ dengan $Y$}

\begin{tabular}{|c|c|c|}
\hline No & $\begin{array}{c}\text { Simbol } \\
\text { statistic }\end{array}$ & Nilai statistic \\
\hline 1 & $\mathrm{~N}$ & 30 \\
\hline 2 & $\sum \mathrm{X}_{2}$ & 1324 \\
\hline 3 & $\sum \mathrm{Y}$ & 114,13 \\
\hline 4 & $\sum \mathrm{X}_{2}^{2}$ & 59446 \\
\hline 5 & $\sum \mathrm{Y}^{2}$ & 438.4019 \\
\hline 6 & $\sum \mathrm{X}_{1} \mathrm{Y}$ & 5066,53 \\
\hline
\end{tabular}

a. Memasukkan data ke dalam rumus

$\sum r_{x_{2} y}=\frac{n \cdot\left(\sum x_{2} y\right)-\left(\sum x_{2}\right) \cdot\left(\sum y\right)}{\sqrt{\left.n \cdot \sum x l^{2}-\left(\sum x_{2}\right)^{2}\right\} .}}$

$=\frac{30.5066,53-1324.114,13}{\sqrt{\left\{30.59446-(1324)^{2}\right\} .}\left\{30.438,4019-(114,13)^{2}\right\}}$

$=\frac{151995,9-15110,1}{\sqrt{\{589,6401\} \cdot\{30404\}}}=\frac{887,78}{\sqrt{3843069}}=\frac{887,78}{1960,375}$

$$
=0,452
$$

a. Menguji nilai (r)

Jadi ada tanda korelasi positif dengan nilai $r_{x 1 y}$ sebesar 0,452 antara hubungan lariSprint50 Meter, kekuatan otot tungkai dengan kemampuanlompat jauh . Untuk menguji hasil $r_{x 1 y}$ signifikan atau tidaksignifikannya, maka perlu dibandingkan dengan r-table. Pada r-tabel apabila taraf signifikan 5\% dan $\mathrm{N}=30$, maka nilai harga $\mathrm{r}$ tabel $=0,361$. Ternyata $r$-hitung lebih besar dari pada r-tabel, sehingga Ha diterima dan Ho ditolak. Jadi kesimpulannya adalah" ada hubungan lari sprint 50 meter dengan kemampuan lompat jauh .

3.

Ringkasan Statistik X1

dengan $\mathrm{X} 2$

\begin{tabular}{|c|c|c|}
\hline No & $\begin{array}{c}\text { Simbol } \\
\text { statistic }\end{array}$ & Nilai statistic \\
\hline 1 & $\mathrm{~N}$ & 30 \\
\hline 2 & $\sum \mathrm{X}_{1}$ & 160.83 \\
\hline 3 & $\sum \mathrm{X}_{2}$ & 1324 \\
\hline 4 & $\sum \mathrm{X}_{1}{ }^{2}$ & 881.8643 \\
\hline 5 & $\sum \mathrm{X}_{2}^{2}$ & 59446 \\
\hline 6 & $\sum \mathrm{X}_{1} \mathrm{X}_{2}$ & 7106.21 \\
\hline
\end{tabular}

a. Memasukkan data kedalam rumus

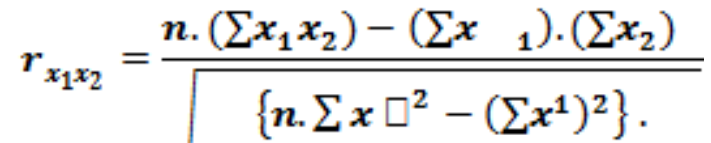

$$
\begin{aligned}
& \sqrt{\left\{n \cdot \sum x \quad 2 \quad \square 2-\left(\sum x \quad 2\right)^{2}\right\}} \\
& =\frac{30.7106,21-16038.1324}{\sqrt{\left\{30.881,8643-(160,83)^{2}\right\}}} . \\
& =\frac{213186,3-212938,9}{\sqrt{\{589,6401\} \cdot\{30404\}}}=\frac{247,38}{\sqrt{17927418}}=\frac{247,38}{4234,078}=0,058
\end{aligned}
$$

a. Menguji nilai (r")

Jadi ada tanda korelasi positif dengan nilai $r_{x_{x_{X X} I}}$ sebesar 0,058 antara hubungan lari sprint 50 meter dengan kekuatan otot tungkai. Untuk menguji hasil $r_{x_{l x 2}}$ signifikan atau tidaksignifikannya, maka perlu dibandingkan dengan r-table. Pada r-tabel apabila taraf signifikan 5\% dan $\mathrm{N}=30$, maka nilai harga $\mathrm{r}$ tabel $=0,361$. Ternyata $\mathrm{r}$-tabel lebih besar dari pada r-hitung, sehingga Ho diterima dan $\mathrm{Ha}$ ditolak.Jadi kesimpulannya adalah "Tidak ada hubungan lari sprint 50 meter dengan kekuatan otot tungkai".

4. Ringkasan Statistik X1 dengan X2

\begin{tabular}{|c|c|c|}
\hline No & $\begin{array}{c}\text { Simbol } \\
\text { statistic }\end{array}$ & Nilai statistic \\
\hline 1 & $\mathrm{~N}$ & 30 \\
\hline 2 & $\sum \mathrm{X}_{1} \mathrm{Y}$ & 0,475 \\
\hline 3 & $\sum \mathrm{X}_{2} \mathrm{Y}$ & 0.452 \\
\hline
\end{tabular}




\begin{tabular}{|l|l|l|}
\hline 4 & $\sum \mathrm{X}_{1} \mathrm{X}_{2}$ & 0.058 \\
\hline
\end{tabular}

a.

Memasukkan

kedalam rumus

$$
\begin{aligned}
& r x_{1} x_{2} y \\
& =\sqrt{\frac{r^{2} x 1 y+r^{22} x 2 y-2 r x 1 y \cdot r x 2 y r x 1 x 2}{1-r^{2} x 1 x 2}} \\
& =\sqrt{\frac{\begin{array}{c}
0,475^{2}+0,452^{2}-2 \cdot(0,475) \\
(0,452) \cdot(0,058)
\end{array}}{1-(0,058)^{2}}} \\
& =\sqrt{\frac{0,429929-0,024905}{1-0,003364}}=
\end{aligned}
$$

b. Jadi ada tanda korelasi positif dengan nilai $R_{x_{1} x_{2} y}$ sebesar 0,637 antara hubungan Lari Sprint 50 Meter dan kekuatan Otot Tungkai dengan KemampuanLompat Jauh $R_{x_{1} x_{z y}}$ signifikan atau tidaksignifikannya, maka perlu dibandingkan dengan r-tabel. Pada r-tabel apabila taraf signifikan 5\% dan $\mathrm{N}=30$, maka nilai harga $\mathrm{r}$-tabel = 0,361 . Ternyata r-hitung lebih besar dari pada r-tabel, sehingga Ho ditolak dan $\mathrm{Ha}$ diterima. Jadi kesimpulannya adalah "Ada hubungan Lari Sprint 50 Meter dan Kekuatan Otot Tungkai dengan prestasi Lompat Jauh.

\section{PEMBAHASAN}

Dari hasil penelitian yang telah dilaksanakan oleh para Siswa SMA Islam Bina Insani Langko menunjukkan bahwa Lari Sprint 50 Meterdan KekuatanOtot Tungkai secara signifikan memiliki keterkaitan pada saat melakukan gerakan Lompat Jauh, yang dimana hasil pengujian hipotesis diterima kebenarannya. Oleh karena itu, ditekankan kepada guru olahraga agar lebih memperhatikan dan meningkatkan lagi kapasitas kemampuan para siswa baik fisik maupun teori supaya hasilnya lebih meningkat lagi.

Dari hasil analisis data dengan menggunakan r-hitung dimana hipotesis alternative (Ha) diterima dan hipotesis nol (Ho) ditolak begitu juga sebaliknya (Ha) ditolak dan (Ho) diterima dengan rincian sebagai berikut:
1. Nilai r-hitung > r-tabel yakni $0,475>0,361$ dengan tarap signifikan 5\% yang dikatakan bahwa "ada hubungan Lari Sprint 50 Meterdengan Kemampuan Lompat Jauh .

2. Nilai r-hitung > r-tabel yakni $0,452>0,361$ dengan taraf signifikan 5\% yang dikatakan bahwa "ada hubungan KekuatanOtot Tungkaidengan Kemampuan Lompat Jauh " dengan perbedaan angka antara r-hitung dengan $\mathrm{r}$ tabel terlalu besar.

3. Nilai r-hitung < r-tabel yakni 0,058>0,361 0,40ctengran taraf signifikan $5 \%$ yang dikatakan

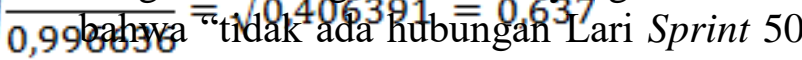
Meterdengan Kekuatan Otot Tungkai" dengan perbedaan angka antara r-hitung dengan r-tabel cukup besar.

4. Nilai r-hitung > r-tabel yakni 0,637> 0,361dengan taraf signifikan 5\% yang dikatakan bahwa "ada hubungan Lari Sprint 50 Meter dan KekuatanOtot Tungkai dengan Kemampuan Lompat Jauh " dengan perbedaan angka antara r-hitung dengan r-tabel begitu besar.

Dari uraian diatas dapat dikatakan bahwa semakin cepat kemampuan Lari Sprint seseorang maka kemampuan lompat jauhnya akan semakin baik karena dengan kecepatan lari yang tinggi seseorang akan memiliki kekuatan dan daya ledak untuk melakukan tumpuan sehingga akan menghasilkan lompatan yang jauh, demikian juga sebaliknya. Berdasarkan hasil penelitian ini berarti ada kemungkinan seorang atlit Lari Sprint 50 Meter dapat menjadi atlit Lompat Jauh .

\section{PENUTUP}

\section{A. Kelimpulan}

Berdasarkan hasil analisa data yang telah dilakukan oleh peneliti dengan menggunakan analisis statistik korelasi product moment diperoleh hasil rhitung 0,475 sedangkan rtabel pada taraf signifikan 5\% adalah 0,361. Dengan demikian hipotesis nol (Ho) ditolak, dan hipotesis alternatif (Ha) yang berbunyi "Ada Hubungan antara kecepatan Lari Sprint 50 Meter dengan Kemampuan Lompat Jauh pada Siswa Putra Kelas XI SMA Islam Bina Insani Langko Tahun Pelajaran 2017/2018 diterima. 
Begitu pula dengan nilai $r_{x 2 y}$ sebesar 0,452dan r-tabel padatarafsignifikan 5\% adalah0,361 sehingga Ho ditolak dan $\mathrm{Ha}$ diterima. Dari hasil penelitian ini, maka peneliti menyimpulkan yaitu "Ada Hubungan kekuatan otot tungkai dengan kemampuan lompat jauh".

Begitu pula dengan nilai $\mathrm{rx} 1 \times 2$ sebesar 0,058dan r-tabel padatarafsignifikan 5\% adalah0,361 sehingga Ho diterima dan $\mathrm{Ha}$ ditolak. Dari hasil penelitian ini, maka peneliti menyimpulkan yaitu "Tidak ada hubungan Lari Sprint 50 Meter dengan Kekuatan Otot Tungkai.

Begitu pula dengan nilai $\mathrm{R}_{\mathrm{x} 1 \times 2 \mathrm{y}}$ sebesar 0,637dan r-tabel pada taraf signifikan 5\% adalah0,361 sehingga $\mathrm{Ha}$ diterima dan $\mathrm{Ho}$ ditolak. Dari hasil penelitian ini, maka peneliti menyimpulkan yaitu "Ada Hubungan lari sprint 50 Meter dan Kekuatan Otot Tungkai dengan Jauhnya Lompatan pada Lompat jauh.

B. Saran

Setelah melakukan penelitian, maka ada beberapa saran yang peneliti sampaikan yaitu:

1. Kepada siswa

agar bersungguh-sungguh dalam melakukan latihan, baik latihan kecepatan lari sprint maupun kekuatan otot tungkai maupun latihan kekuatan demi tercapainya prestasi lompat jauh yang lebih baik.

2. Kepada Guru/Pelatih

Untuk guru/pelatih hendaknya meningkatkan lagi program-program latihan baik pada fisik maupun pada teknik dasar Lari Sprint 50 Meter agar kemampuan para siswa/atlet lebih meningkat lagi. Jika tidak ditingkatkan program latihan tersebut maka kemampuan para siswa/atlet tidak akan meningkat.

3. Kepada Kepala Sekolah

Untuk kepala sekolah seharusnya lebih memperhatikan lagi tentang sarana dan prasarana yang ada disekolah terutama pada sarana dan pranasaran olahraga Lari Sprint agar prestasi siswa/atlet diberbagai cabang olahraga bisa meningkat lebih baik karena dengan olahraga juga bisa meningkatkan kuwalitas sekolah.

\section{Pemerintah}

Untuk kepada para pihak pemerintah agar lebih memperhatikan sarana dan perkembangan untuk peningkatan mutu diberbagai cabang olahraga terutama pada cabang olahraga Lompat Jauh maupun cabang olahra galainya. Pada cabang olahraga Lompat Jauh ini sangatlah banyak yang perlu ditingkatkan lagi baik dari segi atlet, sarana, dan pelatihannya. Kalau tidak diperhatikan oleh pihak pemerintah maka semua diberbagai cabang olahraga terutama Lompat Jauh tidak akan mengalami kemajuan.

5. Kepada Peneliti

Selanjutnya diharapkan agar dapat meneliti pada hal-hal yang sipatnya mendorong peningkatan prestasi olahraga, khususnya Lompat Jauh. Hendaknya mempersiapkan diri untuk melakukan penelitian dan mempersiapkan peralatan penelitian yang akan dibutuhkan pada saat penelitian agar mendapatkan hasil yang diharapkan pada saat melakukan penelitian.

\section{DAFATAR PUSTAKA}

Carr,1997: Atletik. Jakarta PT Ra Grafindo Persada Furchan, Arif. 2004. Pengantar Penelitan Dalam Pendidikan. Yogyakarta: Pustaka Pelajar Offset.

Halim, Ichsan, Nur. 2011. Tes Dan Pengukuran Kesegaran Jasmani. Makasar. Badan Universitas Negri Makasar Http://yenieoey.blogspot.co.id/2013/10Penelitian

Eksperimen-dan-Non.html.

IKIP Mataram. 2011. Pedoman Pembimbing Penulisan Skripsi. Mataram : IKIP Mataram.

Johor, Zainul. 2009. PembelajaranAtletik. Malang. Wineka Media. Maksum, Ali. 2009. Metodologi Penelitian Dalam Olahrag. Surabaya: UNS

Nurhasan. 2000. Tes Dan Pengukuran Pendidikan Olahraga. UPI.Bandung.

Riadi,Mastur. 2009.Raih KebugaranJasmani Melalui Latihan Beban (Weigh Training). Mataram IKIP Mataram.

Riduwan. 2014. Dasar-Dasar Statistika. Bandung: ALFABETA, CV

Sajoto, $\quad$ Mochammad. 1988. PembinaanKondisiFisikDalamOlahra ga. IKIP Semarang. Jakarta

Saputra, Yanis. 2009. Hubungan anatara kecepatan dengan jauhnya lompatan 
JIME, Vol. 4. No. 1

pada lompat jauh gaya jongkok siswa putra kelas VIII SMP Negeri 1 Sikur Tahun Pelajaran 2009/2010. IKIP Mataram. Mataram.

Sugiyono. 2013. Metode Penelitian Administrasi dilengkapi dengan Metode R\&D. Bandung: ALFABETA, $\mathrm{CV}$ 